Max-Planck-Institut für demografische Forschung

Max Planck Institute for Demographic Research

Konrad-Zuse-Strasse 1 - D-18057 Rostock = Germany = Tel +49 (0) 3812081 - 0 - Fax +49 (0) 3812081 - 202 - www.demogr.mpg.de

MPIDR Working Paper WP 2017-013 I May 2017

(Revised October 2019)

Modelling the socio-economic

determinants of fertility:

A mediation analysis using the parametric g-formula

Maarten J. Bijlsma I bijlsma@demogr.mpg.de Ben Wilson

This working paper has been approved for release by: Christina Bohk-Ewald (bohkewald@demogr.mpg.de),

Deputy Head of the Laboratory of Population Health.

(C) Copyright is held by the authors.

Working papers of the Max Planck Institute for Demographic Research receive only limited review. Views or opinions expressed in working papers are attributable to the authors and do not necessarily reflect those of the Institute. 
Accepted for publication at:

Journal of the Royal Statistical Society: Series A (Statistics in Society)

\title{
Modelling the socio-economic determinants of fertility: A mediation analysis using the parametric g-formula
}

\author{
Maarten J. Bijlsma ${ }^{*}$, Ben Wilson ${ }^{2,3}$
}

1. Max Planck Institute for Demographic Research, Rostock, Germany

2. Stockholm University Demography Unit (SUDA), Stockholm University, Stockholm, Sweden

3. Department of Methodology, London School of Economics and Political Science, London, UK

* Corresponding author. E-mail address: bijlsma@demogr.mpg.de

Max Planck Institute for Demographic Research, Konrad-Zuse-Straße 1, Rostock, 18057, Germany.

Tel. +49 (0)3812081 211; Fax: +49 (0)381 2081-439. 


\section{Summary}

Theories predict that the timing of childbearing and number of children born are determined by multiple socio-economic factors. Despite this, many methods are unable to investigate the interrelationships between these determinants, including the direct and indirect influence that they have on fertility over the life course. Here we use the parametric g-formula to examine the interdependent influences of time-varying socioeconomic processes - education, employment status and partnership status - on fertility. To demonstrate this approach, we study a cohort of women who were born in the UK in 1970. Our results show that socio-economic processes play an important role in determining fertility, not only directly but also indirectly. We show that increasing higher education attendance has a largely direct effect on early childbearing up to age 25 , resulting in a substantial increase in childlessness. However, childbearing at later ages is dominated by an indirect effect of education on fertility, via partnership status and employment status, that is twice as large as the direct effect. We also use the gformula to examine bias due to unobserved heterogeneity, and demonstrate that our results appear to be robust. We conclude that the method provides a valuable tool for mediation analysis in studies of interdependent life course processes.

Key words: fertility, socio-economic determinants, mediation, g-formula, UK 


\section{Introduction}

The study of fertility can be seen as an ongoing effort to understand the determinants of human reproduction (Balbo et al. 2012; Becker et al. 1960; Cleland and Wilson 1987; Coale and Watkins 1986; Davis and Blake 1956; Hirschman 1994). There are a variety of interrelated socio-economic determinants - including partnership status, education, and labour market participation - that influence childbearing over the life course (Balbo et al. 2012; Hirschman 1994). In order to understand and predict fertility, it is important to examine the links between these processes, and the collective impact that they have on childbearing (Macura and Beets 2002). Socio-economic determinants of childbearing are a crucial component of most theories that have been used to explain fertility trends over the last fifty years (Becker 1981; Esping-Andersen and Billari 2015; Goldscheider et al. 2015; Hirschman 1994; Lesthaeghe 2010), and are often seen as essential mechanisms in the expression and mediation of theoretical concepts (e.g. Andersson 2004; Forste and Tienda 1996; Johnson-Hanks et al. 2011; Lesthaeghe 1983; Lorimer 1956; Milewski 2010; Neyer et al. 2013; van de Kaa 1987).

Empirical research shows that socio-economic factors are significantly associated with fertility trends in most countries of the world (e.g. Adserà, 2005; Balbo et al., 2012; Bongaarts, 2016; Bongaarts et al., 2017; Dribe et al., 2017; Heaton et al., 2002; Martin, 1995; Reher and Requena, 2015). However, the links between socioeconomic factors and fertility vary across contexts and over time. For example, education is most often negatively associated with female completed fertility (children ever born at the end of childbearing), but in some settings like the Nordic countries this association has weakened over time (Kravdal and Rindfuss, 2008), and appears to have disappeared (see: Jalovaara et al., 2018, which also shows that the association between education and fertility is different for women and men). Similarly, marriage has long been associated with higher fertility, but at the population level fertility is now higher in 
Northern Europe than in Southern Europe, even though marriage rates are also lower (Hoem, 2008). Although these example of heterogeneity are now well-known, much less is understood about they arise and how macro-level trends are determined by micro-level processes, which is one reason why recent research has called for new applications of methods that can extend our existing understanding (Balbo et al., 2012; Billari, 2015).

Empirical research also shows that the socio-economic determinants of fertility are path dependent, simultaneous, and interrelated (e.g. Cohen et al. 2011; Gerster et al. 2014; Kulu and Steele 2013; Lillard and Waite 1993; Steele et al. 2005; Upchurch et al. 2002). For example, economic theories predict that individuals - in particular women will face a series of interconnected socio-economic trade-offs over their life course, including with respect to the timing of education, employment, partnership, and fertility (Billari and Kohler 2004; Dribe et al. 2014; Lee and Mason 2010). Along similar lines, recent sociological research has also emphasized the links between socio-economic choices and the timing of childbearing, including with respect to later-life opportunities (Goisis and Sigle-Rushton 2014; Mclanahan 2004). Each socio-economic process is part of a complex web of time-varying relationships, and may therefore have both direct and indirect effects on fertility, as well as mediating the effects of other socio-economic processes on fertility (Aassve et al. 2006; Buhr and Huinink 2014; Cohen et al. 2011; Upchurch et al. 2002). We therefore define socio-economic determinants as the socioeconomic processes that influence childbearing behaviour, either directly, indirectly, or as mediators.

The complex interrelationships between socio-economic determinants raise a number of methodological issues for empirical research, in particular when studying childbearing over the life course (Balbo et al. 2012). Socio-economic determinants are hard to disentangle, and their influence on life course childbearing is hard to study, even 
when drawing upon the range of methods that are available to social scientists. At the heart of this complexity is the fact that fertility is a time-varying and path-dependent process (Buhr and Huinink 2014; Huinink and Kohli 2014). Researchers are often interested in both the timing of births (the 'tempo' of childbearing), as well as the number of children born (the 'quantum' of childbearing) (Balbo et al. 2012). Moreover, not only is early life course childbearing (or a lack of early life course childbearing) likely to have a direct effect on future fertility, but it is also likely to have indirect effects on future fertility via a number of (mediating) socio-economic processes. For example, becoming a parent may disrupt education or employment (Buhr and Huinink 2014; Upchurch et al. 2002). Previous childbearing is therefore likely to have an impact on the same socio-economic processes that determine future childbearing. Sometimes referred to as reverse causality, this highlights the fact that time-varying socio-economic processes can act simultaneously as causes, effects, and mediators of fertility behaviour. For example, marriage is a determinant of fertility, but may also be determined by fertility, or marriage may act as a mediator for the relationship between another determinant - such as education - and fertility later in life.

As a result of this complexity, previous empirical research has often focused on single determinants of fertility, rather than trying to estimate their interrelationships (Balbo et al. 2012). A common strategy has been to design research that tries to estimate the influence of one determining process, such as partnership status, on fertility (e.g. Brien et al. 1999; Steele et al. 2005). However, when focusing on a single determinant (and treating other determinants merely as confounders), it is hard to examine the interrelationships between different determinants. This is equally true of econometric approaches that seek to minimize bias due to endogeneity (selection and reverse causality) (Engelhardt et al. 2009; Moffitt 2003, 2005). In addition, many of these approaches sacrifice the capacity to generalize (external validity) for a reduction in the 
likelihood of bias due to confounding (Cartwright 2011). Such approaches are wellsuited to answering research questions about single determinants, especially with respect to narrowly defined subsections of the population (such as compliers with an instrumental variable) (Moffitt 2005). However, they are far less useful when attempting to study the interactions between multiple socio-economic determinants of fertility over the life course, or when researchers are keen to make generalizations about the fertility behaviour of broader populations.

In this study, we therefore propose a different approach for the study of multiple fertility determinants. Our aim is not to criticize existing approaches, but rather to expand the methodological toolbox of researchers. In order to do this, we make use of the g-formula, which is a method that has been developed by epidemiologists and biostatisticians over the last few decades (Robins 1986; Robins and Hernán 2009). Similar to other causal inference approaches, the g-formula uses counterfactual theories of causal inference to enable researchers to estimate the effects of a cause (Greenland et al. 1999), such as the hypothetical effect of treatment on the chance of experiencing a cardiac event in the presence of time-varying confounding (Daniel et al. 2013). Another advantage of the g-formula is that it was developed to estimate time-varying effects in the presence of time-varying confounding and mediation (Robins 1986), and is therefore capable of testing hypothetical changes in life course processes while accounting for their interdependency (Robins and Hernán 2009; Daniel et al. 2013; Bijlsma et al. 2017).

This article contributes to both the applied and the methodological literature. From an applied perspective, it is the first time the $\mathrm{g}$-formula has been used to study fertility. This method enables us to model the time-varying determinants of fertility, allowing for selection and reverse causality, while simultaneously investigating the impact of changes to these determinants - in the form of plausible counterfactual 
scenarios. Unlike previous studies, we estimate causal effects at the population-level, rather than for a subset (e.g. compliers with a quasi-experiment), thereby providing findings that are more readily generalisable. Although this paper focusses on fertility, we believe that more generally it represents the first use of the g-formula to study the mediating interrelationships between time-varying life-course processes (rather than merely using the method to control for time-varying confounding). One of our methodological contributions is therefore to show how the g-formula can be used to carry out dynamic mediation analysis (i.e. to examine how mediation changes over time), in particular for an outcome that is both highly path-dependent and monotonic (because an individual's number of children ever born cannot decrease). In addition, we also make a further contribution to the methodological literature by demonstrating, apparently for the first time, how to simulate unobserved confounding in order to carry out sensitivity analysis when using the g-formula. In order to make these contributions, we carry out a case study of fertility in the UK, and our guiding research question is: What are the direct and indirect (mediated) effects of employment status, education, and partnership status on birth risks over the life course for a nationally-representative birth cohort? 


\section{Data}

\section{$2.1 \quad$ Setting}

In common with most high-income countries, the UK has experienced a considerable shift in demographic behaviours over the last fifty years. These include a rise in cohabitation, divorce, and childbearing outside marriage (Beaujouan and Ní Bhrolcháin 2011; Sigle-Rushton 2008). Relative to the rest of Europe, fertility in the UK has remained high, although there are considerable socio-economic differences in both the quantum and tempo of childbearing (Champion and Falkingham 2016; Perelli-Harris et al. 2010). This includes a strong association between birth timing and socio-economic status (postponement of birth for high SES groups), as well as higher completed fertility (children ever born at the end of childbearing) among women who are in the lowest and highest socio-economic groups (as compared with those in between) (Sigle-Rushton 2008). As noted in the introduction, these associations are not observed in every European country outside the UK.

Here we study women in the UK who were born in 1970. Since this birth cohort began their childbearing, there have been a number of changes in the observed associations between childbearing and its most commonly studied socio-economic determinants (Berrington et al. 2015; Berrington and Pattaro 2014; Hobcraft 1996; Kneale and Joshi 2008; O’Leary et al. 2010; Rendall and Smallwood 2003; Steele et al. 2005, 2006). The most prominent determinants of UK fertility trends over the last thirty years include an increased participation in higher education among women, an increase in female employment, and a reduction in the prevalence of marriage (Aassve et al., 2006; Berrington and Pattaro, 2014; Chamberlain and Gill 2005; Neels et al., 2017; Ní Bhrolcháin and Beaujouan, 2012; ONS 2016; Sigle-Rushton 2008; Steele et al. 2005, 2006). 


\subsection{Data source}

Our data come from the 1970 British Cohort Study (BCS70), which follows the lives of around 17,000 people born in a single week of 1970 (UK Data Archive 2016). The sample covers Great Britain, which includes all of the constituent countries of the UK (England, Scotland and Wales), except for Northern Ireland. After dropping all women who have missing information on all variables at the start of our observation period (age 16), we are left with approximately 4,100 women. After this, we drop all cases who have missing data on any one of our baseline covariates, which reduces the sample by around $21 \%$ to just over 3,200 women (Appendix Figure A1). There are no further changes to the analytical sample, such that we carry out complete case analysis, with the addition that women are censored from the year in which they cease to have complete information on all time-varying variables in the analysis. We follow the childbearing life course of these women from age 16 up to age 38 (because the next wave data at age 42 were not yet readily available when we carried out our analysis). According to recently released statistics based on all registered births in England and Wales, the cohort of women born in 1970 had an average completed fertility of 1.9 children per woman at age 45, compared with 1.8 children ever born at age 38 (ONS 2016).

\subsection{Fertility}

Fertility is the primary outcome variable of this study. It is modelled as a time-varying binary variable, with a value of 1 in any year when a live birth occurs, and 0 otherwise. Birth events can result in multiple live born children (i.e. twins or triplets). Although such events are rare for this sample, they are taken into account in the modelling procedure (see below). In addition to births, we include a variable that counts the number of live born children that have occurred up to time $t$ (where $t$ is measured in years, which is the same as age because we are studying a single birth cohort). 


\subsection{Time varying (confounding) mediators and determinants}

The main processes that we study are education, partnership status, employment status, and socio-economic status (with the latter measured only for those who are employed). Each process is measured using annual time-varying indicators derived from the BCS data. We make use of use two education variables: one measuring whether a woman is in full time education or not, and the other counts the number of years spent in full time education. Partnership status is a multinomial variable with three categories, indicating whether a woman is cohabiting, married or single (not in a partnership, regardless of marital history). Where we refer to 'partnership status' in the rest of this article, we refer to this variable. Where we refer to being in a partnership, we mean that women are either cohabiting or married. Employment status is a multinomial variable indicating whether a woman is part-time employed, full-time employed, disabled or unemployed (i.e. not disabled or in any form of employment). The socio-economic status variable indicates whether a woman's employment (full-time or part-time) is of high or low socio-economic status, based on the standard classification of occupations in the UK (UK Data Archive 2016).

\subsection{Time-constant baseline characteristics}

We included a number of (baseline) time-constant variables as control variables, in addition to a time-dependent measure of age. To account for the intergenerational transmission of fertility we include mother's age at birth (when she gave birth to the woman who is being studied) and number of siblings (calculated using information recorded at age 16). We note that the latter may be slightly underestimated, due to unrecorded or unacknowledged siblings, or it may be overestimated due to the inclusion of step-siblings (although for $90 \%$ of respondents this variable is based on questions that ask about 'blood brothers and sisters'). As a measure of parental resources, we use household income at age 10 in three categories (low, medium and high), and as a 
measure of spatial selection we use region of residence at age 16 in six categories (Scotland, Wales, and England North, Midlands, South, and London). Age was measured in three categories, 15-22, 23 to 29 , and 30-38. In the modelling process, the use of a finer age categorization did not strongly impact our population-averaged results. 


\section{Method}

Our method employs the g-formula, which was developed by Robins to estimate timevarying effects in the presence of time-varying confounding and mediation (Daniel et al. 2013; Bijlsma et al. 2017; Robins 1986; Robins and Hernán 2009). The g-formula is implemented in a series of steps. First, we formulate the Directed Acyclic Graph (DAG) in Figure 1, which shows the interrelationships that we investigate. Second, based on the assumed interrelationships that we make explicit in Figure 1, we estimate a series of multivariable generalized linear models (GLMs) for each outcome that is defined by our DAG, and by the variable categories in the BCS70. Third, we define the counterfactual scenarios that are of interest, given our research question. Then, using estimates from these multivariable GLMs, we perform a series of micro-simulations to produce each counterfactual scenario, including to estimate total, direct, and indirect effects. In addition to these g-formula steps, we perform a sensitivity analysis to examine the influence of unobserved heterogeneity. The code for our analysis is provided as a supplement to this article, and the data are available from the UK Data Archive (2016).

\subsection{Directed Acyclic Graph (DAG)}

The presence of time-varying variables, confounders, mediators, and outcomes, is illustrated by the DAG in Figure 1. Control variables are allowed to affect all timevarying determinants, but are not shown. The existence of time-varying determinants is evident from the arrows between each of the other processes and fertility. Reverse causality is evident from the paths that lead away from fertility in one year, and return to fertility in a future year. The relationship between fertility and itself is therefore mediated by each of the other time-varying processes. 
Figure 1: Directed acyclic graph of fertility and time-varying mediating confounders
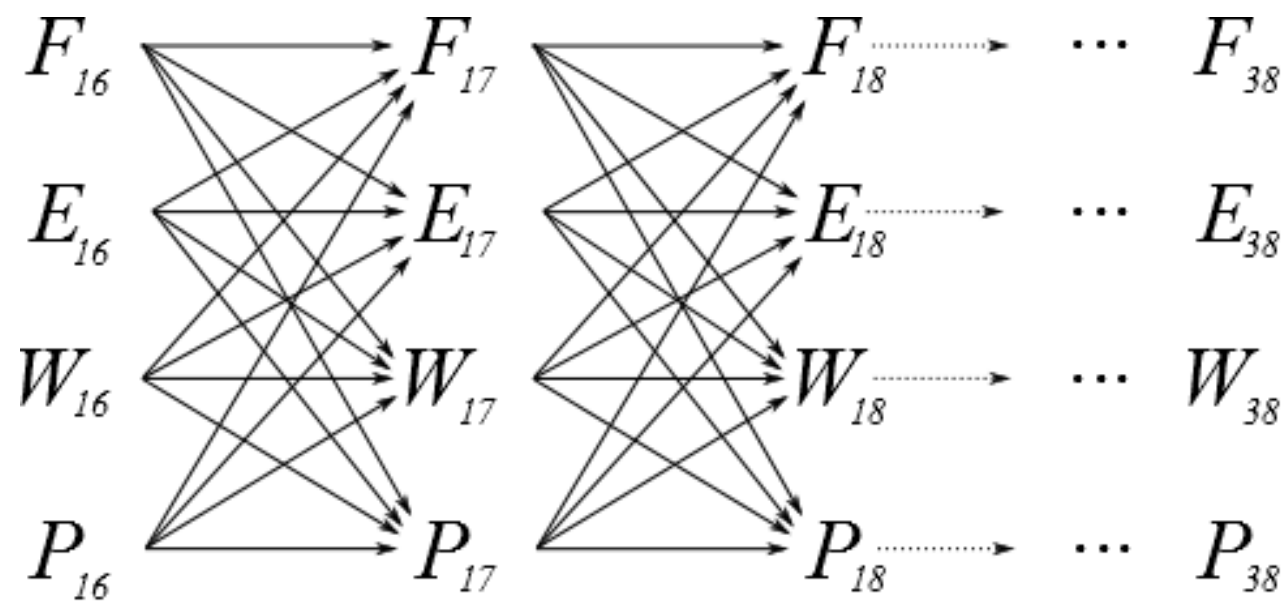

Each letter represents a time-varying variable as follows: $\mathrm{F}=$ Fertility, $\mathrm{E}=$ Education, $\mathrm{W}=$ Work (employment status), and $\mathrm{P}=$ Partnership status. Each arrow represents a causal relationship in the direction indicated by the arrow. Only the relationships between age 16 and 18 are shown since the relationships are the same from each year to the next. Note that time-constant baseline characteristics - parental income, mother's age at birth, number of siblings, and region - are not shown because these are modelled to have a direct effect on every time-varying process in every year. The same is true of age. All models include interactions between age and partnership, fertility and education, fertility and partnership, and fertility and employment. Fertility is modelled using 'birth in a given year', and the lagged equivalent as shown. This outcome is then adjusted to account for multiple births, which enables a cumulative count of 'children ever born' to be estimated and used as a control variable in each of our simultaneous equations.

\subsection{Multivariable modelling}

We model the interrelationships between four social processes, each measured using a series of binary variables as follows: fertility (one binary variable), education (one binary variable), partnership status (three binary variables) and employment status (four binary variables). Let $Y_{g t+1}$ denote a variable measured at time $t+1$, where $g$ is an index for members of the set $G$, which contains the following binary outcomes: birth in the last year, in full-time education, single, cohabiting, married, out of work, working part-time, working full-time, disabled, low socio-economic status, high socio-economic status. $M_{h t}$ denotes the values of a mediating covariate measured at time $t$, where $h$ is an index for members of set $H$, which contains the same variables as $G$, as well as total education (a cumulative count of years of education) and total births (a cumulative count of number of live-born children). To define the other explanatory variables, let $B_{c}$ be a time-constant variable measured prior to age 16 , where $c$ is an index for members of set $C$, which contains: parental income at age 10, age of mother at respondent's birth, 
number of siblings, and region. Let $A_{k t}$ be a categorical indicator variable for age (where $\mathrm{k}=15-22,23-29$, or 30-38) measured at time $t$. Finally, let $L_{j t}$ be a series of interaction terms, where $j$ is an index for members of set $J$, containing: employment status interacted with socio-economic status, age interacted with partnership status, and childlessness (total births $=0$ ) separately interacted with education, all three partnership status variables, and all four employment status variables. Conditional on the explanatory variables, $Y_{g t+1}$ is taken to follow a logistic distribution, and is modelled as:

$$
\operatorname{logit}\left\{E\left(Y_{g t+1}\right)\right\}=\eta+\alpha_{k} A_{k t}+\sum_{c \in C} \beta_{\mathrm{c}} B_{c}+\sum_{h \in H} \mu_{h} M_{h t}+\sum_{j \in J} \lambda_{j} L_{j t}
$$

where the coefficients $\alpha, \beta, \mu$ and $\lambda$ are estimated for each of their subscripts $(k$, $c, h$, and $j$, respectively), and then this estimation procedure is repeated for each of the outcomes $Y$ (as indicated by the subscript $g$ ). We also note that the distinct categories of each multinomial variable (e.g. the three partnership status categories) were modelled using logistic regression in the simulation step of the g-formula. As compared to using multinomial regression, this made no difference to our results, but it did improve the efficiency of our code considerably.

\subsection{Counterfactual scenarios}

As summarised in Table 1, we examine the impact of three scenarios on fertility. In the first two, we set out to examine the effect of large-scale demographic changes on fertility. These scenarios are based on observed trends in the UK from 1970 until the present day: increases in higher education attendance among women (scenario \#1), and a reduction in the prevalence of marriage (\#2). As well as these trend-based scenarios, we also examine the effect of a hypothetical policy intervention to increase the postbirth employment of women (\#3). 
Table 1: Estimated scenarios

\begin{tabular}{ll}
\hline Scenario & Details \\
\hline $\begin{array}{l}\text { 1: Increase in higher } \\
\text { education attendance }\end{array}$ & $\begin{array}{l}\text { We randomly select a group of women from those who } \\
\text { are still in education at age 16, and then keep them in } \\
\text { education until age 22, so that at least 50\% of all women } \\
\text { remain in (higher) education until age 22. }\end{array}$ \\
\hline $\begin{array}{l}\text { 2: Reduction in the } \\
\text { prevalence of marriage }\end{array}$ & $\begin{array}{l}\text { We simulate a decrease in the proportion of women who } \\
\text { are married, and a corresponding increase in the } \\
\text { proportions single and cohabiting, equivalent to a 50\% } \\
\text { reduction in the stock of married women over the study } \\
\text { period. }\end{array}$ \\
\hline 3: Increase in post-birth \\
employment
\end{tabular}$\quad \begin{aligned} & \text { We ensure that all women, except those who are } \\
& \text { disabled, are employed full-time in the year after their } \\
& \text { birth (after which time they are free to follow any } \\
& \text { employment trajectory). }\end{aligned}$

\subsection{Total effect estimation}

To determine the effect of each of the counterfactual scenarios, we first produce a scenario without an hypothetical intervention, commonly referred to as the "natural course' scenario in the literature (Keil et al. 2014). Each counterfactual scenario is then compared to the natural course in order to determine its total effect. The outcome of a scenario (natural course or intervention) is estimated using the parametric g-formula:

$$
\begin{aligned}
E\left[Y_{\bar{x}}\right]= & \sum_{\left(m_{1}, \ldots, m_{T}\right)}\{E[Y \mid \bar{X}=\bar{x}, M=m] . \\
& \left.\prod_{t=1}^{T} P\left(M_{t}=m_{t} \mid \bar{X}_{t-1}=\bar{x}_{t-1}, M_{t-1}=m_{t-1}\right)\right\}
\end{aligned}
$$

where $Y_{\bar{x}}$ is the outcome of interest (e.g. total births at the end of follow-up) when some intervention on $x$ has taken place, and $M$ represents the time-varying mediators that we do not actively change with the intervention. In the g-formula, we also condition on age $\left(A_{k t}\right)$ and the baseline covariates $\left(B_{c}\right)$ from equation (1), as well as including the interaction terms $\left(L_{j t}\right)$ from the same equation. However, we have omitted these from equation (2) for brevity, and because they are either not causally 
affected by the intervention (in the case of $A_{k t}$ and $B_{c}$ ) or are deterministic functions of the mediators (in the case of $L_{j t}$ ).

The intervention is here represented by $\bar{x}$, with the variable that takes the place of $x$ dependent on the specific scenario. Since in complex settings this summation may be analytically intractable, a simulation step, i.e. Monte Carlo integration, is used instead (within a bootstrap to determine standard errors). This simulation is composed of the following sub-steps:

1: draw one random sample of individuals with replacement from the data

2: (re-)estimate earlier specified multivariable models

3: draw a dataset for starting values at baseline / 'first' year of follow-up

4: use multivariable models to predict outcomes for the 'second' year of follow-up

5: repeat step 4 for all years of follow-up, given (predicted) values at previous year

6: save results and go back to step 1

7: repeat steps 1-6 for each iteration (999 times)

8: report the estimates and corresponding uncertainty

These 8 sub-steps produce the natural course $E\left[Y_{x}\right]$. The natural course is not exactly the same as the empirical data, but should approximate it, and is essentially a simulation of the empirical data with uncertainty (sub-step 1 generates the uncertainty). In the simulation, whenever a birth is predicted, it has a chance of being a multiple birth (e.g. twins) based on empirical probabilities of a multiple birth (by number of live-born children).

To produce the intervention scenarios, we perform these same 8 sub-steps but between sub-steps 4 and 5 we perform the 'intervention' as described in Table 1. For example, in scenario 3 - an increase in employment after birth - a woman who had a birth in the last year and is predicted to be unemployed (by the multivariable models), is 
mechanically set to be employed instead. Performing the sub-steps this way produces $E\left[Y_{\bar{x}}\right]$. To account for covariance, we perform both the sub-steps for the natural course scenario, and for an intervention scenario, and compare their outcomes within each bootstrap iteration. This produces the total effect (TE): $E\left[Y_{x}-Y_{\bar{x}}\right]$. Note that $E\left[Y_{x}-\right.$ $\left.Y_{\bar{x}}\right]$ can also be written as $E\left[Y_{x M_{x}}-Y_{\bar{x} M_{\bar{x}}}\right]$ to denote that the values of the (other) mediators also change as a function of intervening on $x$.

\subsection{Mediation: direct and indirect effects}

We estimate the direct and indirect effect of each intervention on fertility for both the education and the marriage scenarios (we omit the post-birth employment scenario from this part of the analysis due to its small effect size). Given our DAG, the indirect effect of marriage can be via education or employment status, whereas the indirect effect of education can be via partnership status or employment status. To estimate these indirect effects, we use effect decomposition (Pearl 2001; Robins and Greenland 1992; VanderWeele 2014; VanderWeele and Vansteelandt, 2009). More specifically, we decompose the total effect (TE) into the total direct effect (TDE) and the pure indirect effect (PIE) (Wang and Arah 2015). The TDE is determined like the TE, except the covariate values of mediating variables are drawn from the natural course, so that the effect of the scenario of interest on the outcome can no longer act via these mediators and is thus only a direct effect, i.e. $E\left[Y_{x M_{x}}-Y_{\bar{x} M_{x}}\right]$. For example, changes in the prevalence of marriage can now only affect fertility directly - as shown in our DAG by arrows from $\mathrm{P}$ to $\mathrm{F}$ - and not via employment status or education because values for these mediators are drawn from the natural course. Furthermore, PIE $=$ TE - TDE $=$ $E\left[Y_{x M_{x}}-Y_{\bar{x} M_{\bar{x}}}\right]-E\left[Y_{x M_{x}}-Y_{\bar{x} M_{x}}\right]=E\left[Y_{\bar{x} M_{x}}-Y_{\bar{x} M_{\bar{x}}}\right]$. We note that other mediation effect decompositions are also possible (Wang and Arah 2015).

\subsection{Sensitivity to unobserved confounding}


The g-formula relies on the assumption that the most important sources of confounding are observed. As such, sensitivity analysis is particularly useful in order to test the susceptibility of results to unobserved confounding (unobserved heterogeneity). We focus here on the same scenarios as in the mediation analysis.

We draw upon recently proposed approaches to simulate the influence that a hypothetical unobserved confounder would have on our results (Carnegie et al. 2016; Lin et al. 2017; VanderWeele 2015), and extend them to the g-formula. This is done by constructing an artificial confounder $C$, as a function of the variables it confounds $(X$ and $Y$ ), and then determining how much its inclusion changes the outcome of interest, as follows:

(i) Assume an equation for confounder $C$ as a function of the variables it confounds, e.g. $C_{i}=\beta_{0}+\beta_{\mathrm{x}} X_{i}+\beta_{\mathrm{y}} Y_{i}+\varepsilon_{i}$

(ii) Set values for $\beta_{x}, \beta_{y}$ and $\varepsilon_{i}$ that seem reasonable.

(iii) Predict $C$ based on equation 3, that is, including random $\varepsilon_{i}$ for each prediction.

(iv) Fit the regression $\mathrm{E}[\mathrm{X} \mid \mathrm{C}]=\theta_{0}+\theta_{1} C$, and fit the regression $\mathrm{E}[\mathrm{Y} \mid \mathrm{X}, \mathrm{C}]=\gamma_{0}+$ $\gamma_{1} C+\gamma_{2} X$

(v) Check $\theta_{1}$ and $\gamma_{1}$, these are the effects of $\mathrm{C}$ on $\mathrm{X}$ and $\mathrm{Y}$. When the model for $\mathrm{Y}$ is collapsible, check $\gamma_{2}$ to immediately see how the effect of the determinant of interest $(\mathrm{X})$ on $\mathrm{Y}$ changes due to control for the hypothetical confounder. If the model for $\mathrm{Y}$ is non-collapsible, such as in our case, a population-averaging step (such as the scenario comparison step of the g-formula) is needed.

(vi) Depending on the findings of step (v), return to step (i) and adjust $\beta_{x}, \beta_{y}$ and/or $\varepsilon_{i}$ to adjust $\theta_{1}$ and $\gamma_{1}$, where $\varepsilon \sim N\left(0, \sigma^{2}\right)$.

Including this artificial $C$ in a model for the effect of $X$ on $Y$ will change the estimated effect of $X$, and this change can be assumed to represent the impact of an (hypothetical) 
unobserved confounder (if it were instead observed and included in the analysis). Strictly speaking we have created a collider, but from the perspective of statistical associations, confounders and colliders are two sides of the same coin. Adjusting $\beta_{x}, \beta_{y}$ and $\varepsilon_{i}$ will change the values of $\theta_{1}$ and $\gamma_{1}$. Once $\beta_{x}$ and $\beta_{y}$ have been set, an easy way to adjust the overall strength of the confounder is then by adjusting $\varepsilon$. Increasing random variation weakens the relationship of the confounder with $X$ and $Y$, and vice versa.

We note that $C$ does not need to represent one confounding mechanism: it can also represent the joint effect of a number of confounders. We use an iterative procedure here because in non-linear settings it is difficult to determine the values of $\beta_{x}, \beta_{y}$ and $\varepsilon_{i}$ that are required to produce statistically or theoretically plausible $\theta_{1}$ and $\gamma_{1}$ values. For various analytical solutions, see VanderWeele (2015).

This sensitivity analysis is applied to the education scenario and the marriage scenario, both of which may be affected by unobserved confounding. In the marriage scenario, we motivate our analysis by assuming - based on the literature - that certain individuals have a more 'traditional' value system, obtained during childhood, which makes them more likely to get married and have children (e.g. Guetto et al. 2015; Hirschman 1994; Inglehart and Baker 2000; Lesthaeghe 1983). Our analysis is motivated by the idea that traditional values of this kind most certainly existed for the 1970 birth cohort, at least for a subset of the population. If such a variable could be measured, it would function as a baseline confounder (and in some research contexts would be known as a selection effect). Indeed, it is also reasonable to ignore what this variable represents and instead view it as a more general test of sensitivity to unmeasured baseline confounding.

We generate this confounder based on each individual's observed number of children and total years spent in marriage at age 38 (i.e. both the outcome and 
exposure), setting the coefficient for the former to 3 and the latter to 1 (in step (i) above). Initially, $\varepsilon_{i}$ was set to be normally distributed with a mean of 0 and standard deviation of 7. The confounder score $C$ of an individual was then assigned to all observations of that respective individual (i.e. all ages before age 38 , because we define the confounder to be a baseline or time constant confounder). This produces what we refer to as the 'strong' confounder. Then, to determine the strength of unobserved confounding that is needed to completely make our intervention effect non-significant, we generated even stronger confounders by changing $\varepsilon_{i}$ to have a standard deviation of 3.5 (a 'stronger' confounder) and finally of 1 (the 'strongest' confounder).

For the education scenario, we assumed that traditional values may make a woman more likely to have children and less likely to be in education (e.g. Guetto et al. 2015; Hirschman 1994; Inglehart and Baker 2000; Lesthaeghe 1983). The confounder was constructed in a similar way as in the marriage scenario, with a coefficient of 3 for total number of children, -1.95 for total person-years in education, -1.15 for total number of years in fulltime employment, and -0.65 for women in part-time employment. Standard deviations of $\varepsilon_{i}$ were 10, 5 and 1 for the 'strong', 'stronger' and 'strongest' confounding variants, respectively. 


\section{Results}

\subsection{Multivariable models}

Before presenting results that indicate the effects of each scenario, we briefly discuss some model diagnostics. Although the results from the multivariable models in equation (1) cannot be interpreted in full, because they represent only one step of the g-formula procedure, they are similar to those that would be obtained using a traditional panel model. For this reason, some analysts use these results to check that estimated coefficients are coherently aligned with expectations. Unexpected values of parameters are not necessarily incorrect, but may warrant further investigation. Appendix Table A1 shows that our models align with the results of previous research on fertility. For example, a decreased risk of birth is associated with being single, employed, or in fulltime education. Appendix Table A2 shows another form of model diagnostic, a comparison between the natural course and the empirical data. In our analysis, it appears that the g-formula does a good job of predicting cumulative fertility at age 38 , although with some small differences from the empirical data. There is a slight underestimation of childlessness, although this is likely to be due, at least in part, to the censoring in our empirical subsample.

\subsection{Results from the g-formula}

Figure 2 shows the results of the three scenarios (described in Table 1), as compared with the natural course. The first of these examines the impact of an increase in higher education attendance among women. Not only is there a significant negative impact on the quantum of fertility across most of the reproductive life course, but there also appears to be a strong impact on the tempo of fertility. Educational attendance has a suppressive effect on fertility, but this effect is most dominant while women are attending higher education. In our scenario, cumulative fertility is lowest (relative to the natural course) when women leave higher education - at around $75 \%$ of the level it 
would be otherwise. From this point onward, the women in this scenario catch-up with women in the natural course - exhibiting an increase in fertility tempo. By age 38 , their number of children ever born is around $90 \%$ of the level that it would be in absence of the scenario.

The second scenario examines the impact of a reduced prevalence of marriage. As with the education scenario, this is based on observed demographic trends, which in this scenario refer to a reduction in marriage that is accompanied by an increase in the prevalence of unmarried cohabitation or not living in a residential partnership (i.e. being single). The impact of this scenario is also significant, but with a steadily increasing effect over time. By age 38, this scenario leads to a reduction in children ever born of around $13 \%$.

The post-birth employment scenario shows much weaker effects (although $\mathrm{p}<0.05$ at age 38 ). In this scenario we examine the impact of a hypothetical policy intervention that increases post-birth employment. The results of this scenario are similar to that of the marriage scenario, but less strongly significant. This might be expected because we only adjust employment rates in the year immediately after birth, and allow them to vary after that. However, it is also due to the relative strength of the (conditional) relationship between partnership status and fertility as compared with employment status and fertility. Based on our assumptions, a scenario in which all women took on full-time employment the first year after birth would result in around $5 \%$ fewer births.

In addition to the impact on average fertility, the g-formula can be used to show the impact of each scenario on the distribution of births by age and parity (Table 2). Here we only show results for the middle and end of the childbearing life course (age 28 and 38). The results concur broadly with those in Figure 2. For example, they indicate 
the postponement of childbearing in the education scenario at age 28, (a nine percentage-point difference as compared with the natural course). In addition, these results show that the relationship between parity and effect size is not necessarily straightforward. For example, the employment scenario makes no discernible difference to the level of childlessness at age 38 , but instead leads to a reduction in fertility levels due to fewer births at higher parities $(3+)$. This can be contrasted with the marriage scenario, which appears to have a strong impact on both childlessness and higher parity births.

Table 2: Parity distributions at ages 28 and 38

\begin{tabular}{|c|c|c|c|c|c|c|c|c|}
\hline \multirow[b]{2}{*}{ Parity: } & \multicolumn{4}{|c|}{$\begin{array}{c}\text { Percentage of women } \\
\text { age } 28\end{array}$} & \multicolumn{4}{|c|}{$\begin{array}{c}\text { Percentage of women } \\
\text { age } 38 \\
\end{array}$} \\
\hline & $\mathbf{0}$ & 1 & 2 & $3+$ & $\mathbf{0}$ & 1 & 2 & $3+$ \\
\hline Natural course & 47 & 26 & 22 & 5 & 22 & 20 & 39 & 19 \\
\hline 1: Education scenario & 56 & 22 & 17 & 5 & 28 & 19 & 35 & 18 \\
\hline 2: Marriage scenario & 51 & 26 & 20 & 3 & 29 & 21 & 35 & 15 \\
\hline 3: Employment scenario & 47 & 28 & 21 & 4 & 22 & 22 & 41 & 15 \\
\hline
\end{tabular}

Note: These two ages are shown to illustrate the results, but the same comparison could be made at any age. 
Figure 2: Scenario impact on fertility over the life course
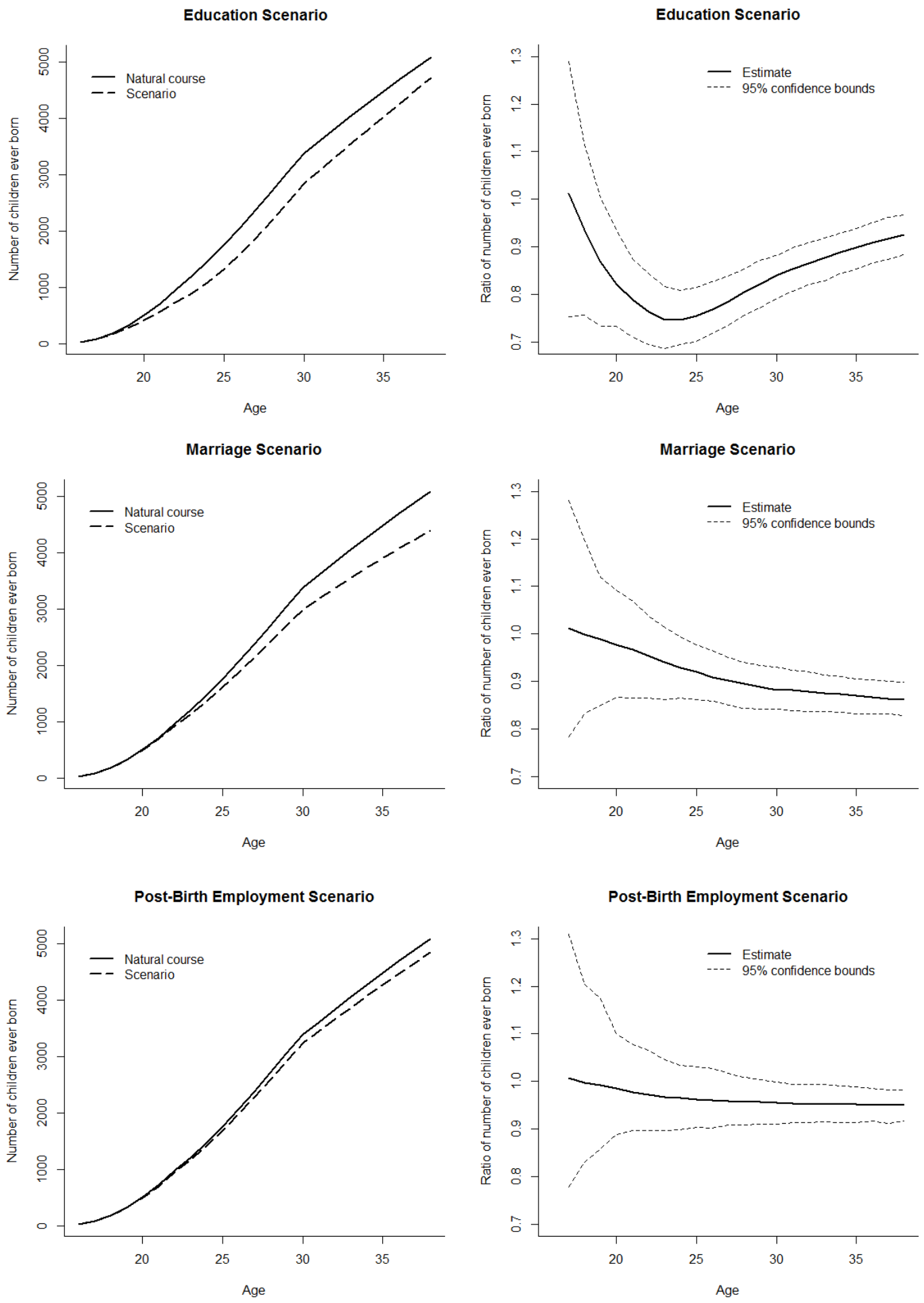

Note: The plots on the left-hand side indicate the total number of children born in our sample, by age. To the righthand side of each of these plots is a plot of scenario results as compared with the natural course, calculated as a risk ratio, and accompanied by $95 \%$ confidence intervals. 


\subsection{Mediation Analysis}

We perform a mediation analysis for the two scenarios with the most significant results: the education scenario (\#1) and marriage scenario (\#2). Given that we have annual data, and the ability of the g-formula to perform a mediation analysis at each time point, we are not only able to estimate mediation at the end of follow-up, but also at every year $t$. We decompose the total effect (TE) into the total direct effect (TDE) and pure indirect effect (PIE), where the latter shows the profile of mediation at each age (Figure 3). As a share of the total effect, the direct effect is initially large in both scenarios. However, the life course profiles of mediation are very different.

In the education scenario, the indirect effect is fairly small (5-15\% of the TE) during the years in which the scenario increases educational attendance (up to age 23), but it declines rapidly from ages $24-26$, after which mediation becomes more dominant than the direct effect of education on fertility. This analysis shows that education has a strong indirect effect on fertility, mediated by partnership status and employment status (e.g. educational attendance reduces fertility indirectly by increasing employment and reducing marriage or cohabitation). It follows that these indirect effects are important for determining reductions in the number of children born at later childbearing ages, and for the profile of recuperation that is observed in Figure 2.

In the marriage scenario, we observe a very different pattern of mediation. Apart from age 17 (when the TE is itself fairly small), the direct effect is consistently larger than the indirect effect, and after age 25 it is not only dominant but almost entirely responsible for the total effect. The only ages where mediation has a sizeable effect are from 18-24. At ages 19 and 20, the size of the indirect effect is more than $50 \%$ of the total effect. Perhaps most interestingly, the direction of the indirect effect at younger ages is different from the direct effect, which in some cases - from ages 18-27 - is more than $100 \%$ of the total effect. This is not an error, but instead implies that mediation 
operates in the opposite direction from the total effect, thereby suppressing some of the direct effect. Since the total effect is a reduction in fertility, mediation from ages 18-27, via education and employment status, thereby serves to increase fertility (e.g. marriage increases fertility indirectly by reducing education and employment). As with the education scenario, this analysis shows that socio-economic processes are important determinants of fertility in their role as mediators, in addition to the direct relationships that they have. We are not aware of previous research that has estimated both the direct and indirect (mediating) effect of multiple socio-economic processes on fertility, either for the UK, or in other contexts.

\subsection{Unobserved confounding}

When added to our multivariable models, the 'strong' unobserved confounder that we simulate for the marriage scenario increases the yearly odds of marriage by 4.0 and the odds of childbirth in each year by 1.6. Comparing these odds ratios to exponentiated coefficients from the multivariable models shown in Table A1, we note that the effect of this unobserved confounder (on marriage) is stronger than all observed conditional relationships, except for the lagged effect of marriage on itself. Similarly, its effect on birth is stronger than that of all baseline covariates and many of the time-varying covariates. Taken together, we therefore conclude that this is a strong confounder. Conclusions for the education scenario are roughly similar. In the education scenario, the 'strong' confounder increases the yearly odds of not being in education of 1.6 and the odds of childbirth in each year by 1.8 (when added to our multivariable models).

Despite our view that these are strong confounders, we also generate two even stronger confounders. For marriage, the first increases the odds of marriage by 9.0 and birth by 2.4 , and the second increases the odds of marriage by 16.0 and birth by 3.0 . In order to evaluate the sensitivity of our analysis (and conclusions) to unobserved 
confounding, we then control for this confounder in our analysis, once at each strength, and compare the natural course to the marriage scenario.

Our sensitivity analysis shows how our results would be changed in the marriage or education scenarios after accounting for (hypothetical) unobserved confounding (Figure 4). The substantive results are only changed in the case of the strongest hypothetical confounder, suggesting that unobserved heterogeneity could only make a relevant difference in this case. The results remain statistically significant in the two other confounding analyses, at early childbearing ages for the education scenario, and at later childbearing ages for the marriage scenario.

We take these results to mean that our conclusions are robust to unmeasured confounding. This is based upon our view that unobserved confounding is unlikely to be as strong in reality as in any of our confounding scenarios, in particular the strongest scenario. In reaching this conclusion, we acknowledge that there could be unobserved factors that are as strong as those that we generate. However, with the exception of the variables that are included in our analysis, we are not aware that such factors have been observed in the demographic and sociological literature on fertility. 
Figure 3: Total direct effect (TDE) and pure indirect effect (PIE) as percentage of total effect (TE)

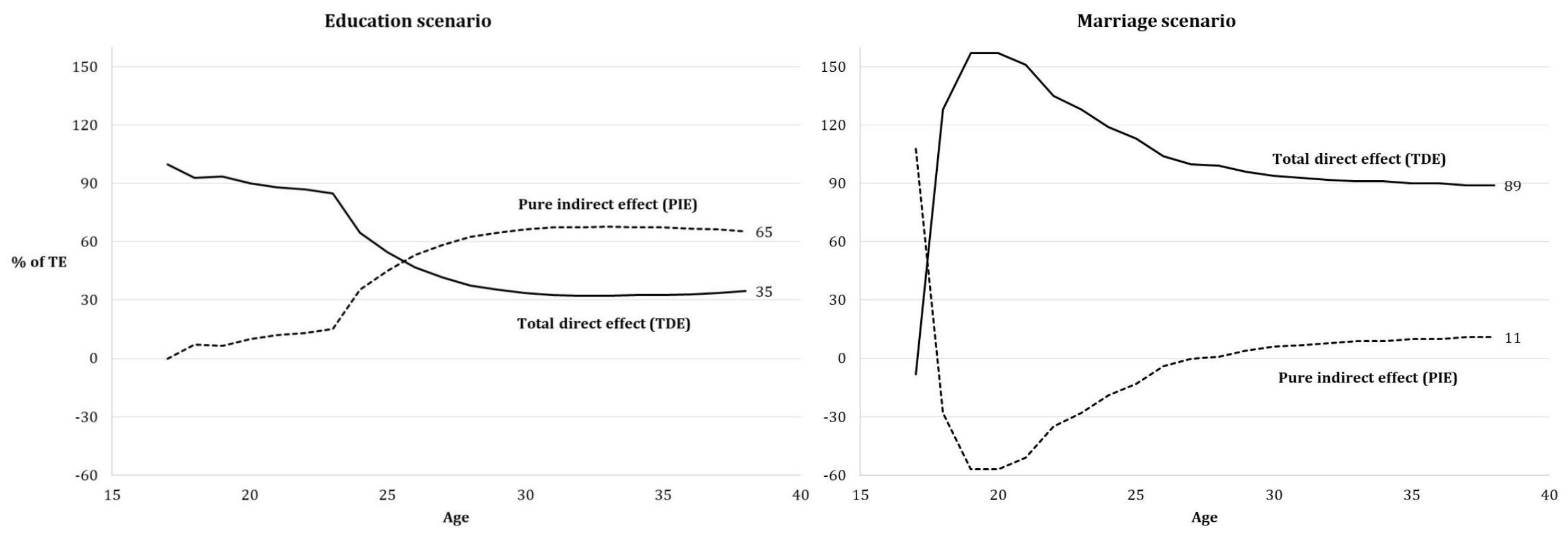

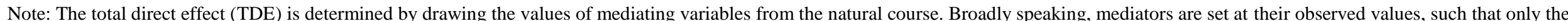
direct effect remains. The pure indirect effect (PIE) is calculated as (TE-TDE)/TE - and defined as the proportion of the total effect (TE) that would be eliminated by intervening to set the mediators

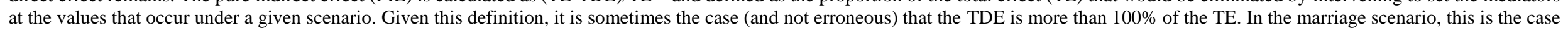
for ages 27 and under, and implies that mediation operates in the opposite direction from the total effect, thereby suppressing some of the direct effect. 


\section{Figure 4: Sensitivity analysis for the impact of unobserved confounding on the education (left) and marriage (right) scenarios}
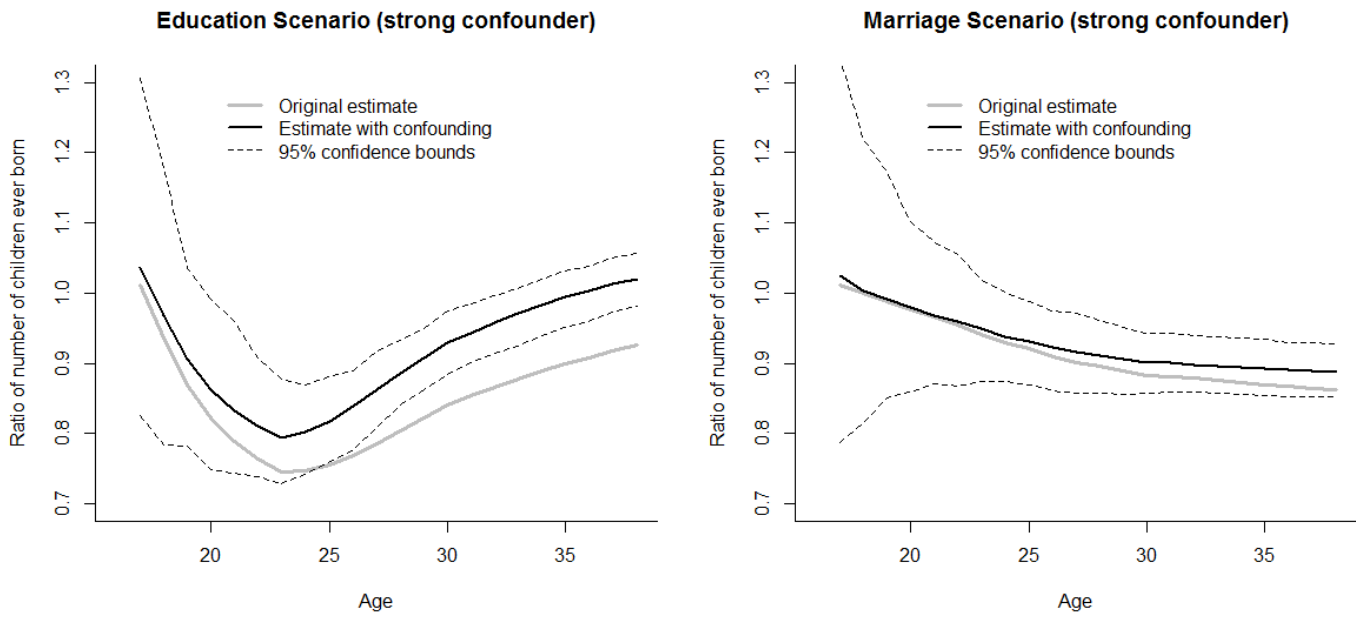

Education Scenario (stronger confounder)
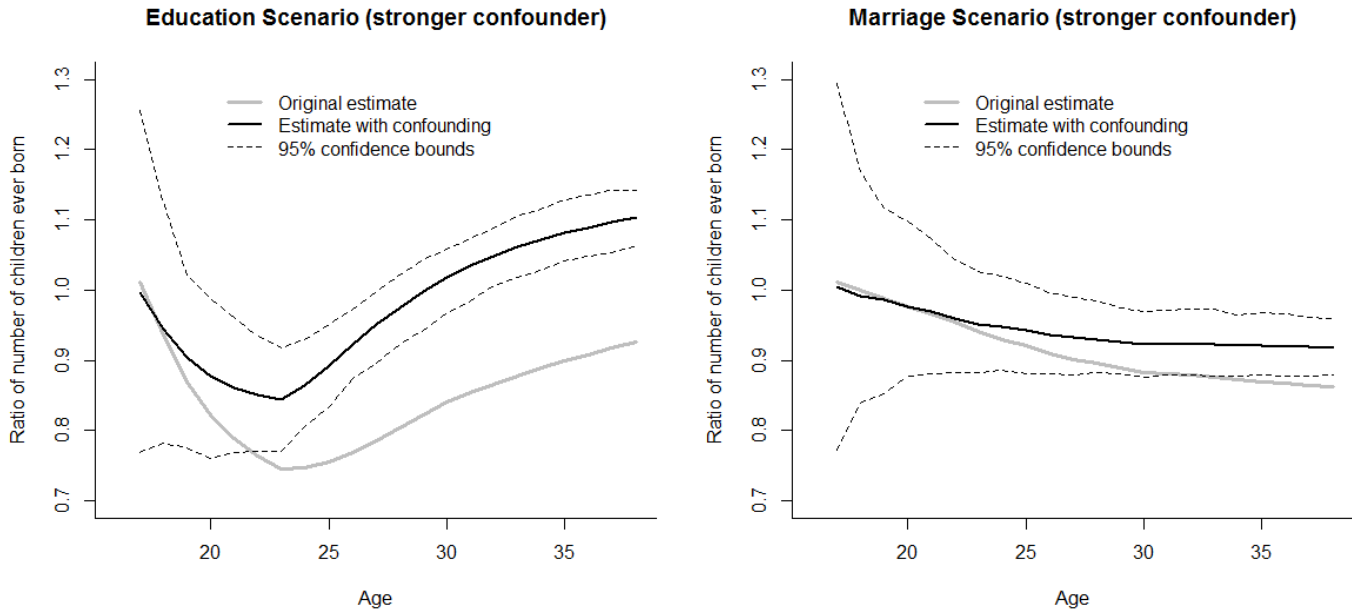

Education Scenario (strongest confounder)

Marriage Scenario (strongest confounder)
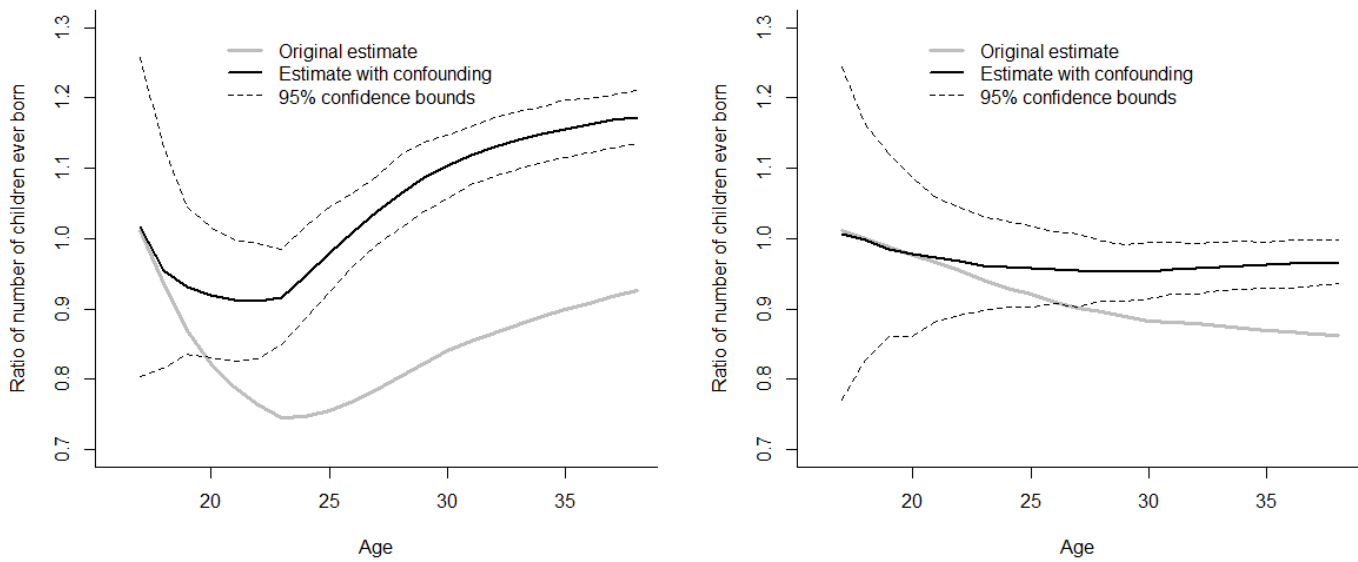

Note: This plot compares the effect of an unobserved confounder between education and fertility (left) and between marriage and fertility (right) which we generate at three different levels of strength. For education, at each year of follow-up, the strong confounder has odds ratios on not being in education and on birth, respectively, of 1.6 and 1.8, the stronger confounder of 2.3 and 2.9, and the strongest of 2.9 and 5.6. For marriage, the odds ratios on marriage and births respectively of the strong confounder are 4 and 1.6, the stronger 9 and 2.4, and the strongest 16 and 3. Original estimates are the same as those found in Figure 2 (right hand side). 


\section{Discussion}

In this article, we have shown that education, partnership status, and employment status are all significant in determining fertility, but to different degrees, and with different profiles over the life course. Moreover, our results help to disentangle the direct and indirect (mediated) effects of these determinants, while showing how the g-formula can be used to examine bias due to unobserved heterogeneity. Previous research has focussed almost exclusively on estimating the total effects. Here we calculate direct and indirect effects for two scenarios - an increase in higher education attendance, and a reduction in the prevalence of marriage - both of which represent realistic demographic changes. We show that the role of socio-economic mediation can be very different, dependent upon the socio-economic processes, and stage of the life course that are considered.

On the one hand, the effects of marriage and education are similar, in that they are both important determinants of fertility. Other studies of the UK have also found significant total effects for these factors (Berrington and Pattaro, 2014; Neels et al., 2017; Ní Bhrolcháin and Beaujouan, 2012; Steele et al. 2005, 2006). Similarly, the fact that we find only a small effect of employment (for our limited scenario) also aligns with prior research which shows that "different levels of labour force participation by females do not necessarily lead to large changes in fertility events" (Aassve et al., 2006, p.781).

On the other hand, with respect to their direct and indirect effects, they are very different. The indirect effect of marriage, via education and employment status, is relatively small, as compared to its direct effect on fertility at age 38. At early childbearing ages, the indirect effect of marriage only serves to partly counteract its direct effect on fertility. In contrast, the indirect effect of education, via partnership status and employment status, is in the same direction as the direct effect at all ages. 
Moreover, the indirect effect of education is much larger than the direct effect after age 27. This implies that mediation plays a much more prominent role in determining the effect of education on fertility than the effect of marriage on fertility, at least at later childbearing ages. Taken together, these results show that socio-economic processes play an important role in determining fertility, not only because of their direct and indirect effects, but also in their role as mediators. To the best of our knowledge, previous empirical research has yet to provide such evidence.

In the final stage of our analysis we examine the sensitivity of our results to unobserved confounding. This is an important extension because it addresses one of the main assumptions of our approach, namely that the most important sources of confounding are observed. There may be some confounders that are not included in our analysis, but the essential question is whether they would make a difference to our findings. Based on our sensitivity analysis, it appears they would not. In reaching this conclusion, we recognize that there are other ways of specifying unobserved confounding, although we have attempted to choose a rigorous and transparent approach.

Nevertheless, unobserved confounding is not the only limitation of our analysis. In common with many previous studies, our analysis is limited to only those women who had complete data for all variables at baseline and in the first year of observation. As such, our analysis is susceptible to assumptions regarding missing data, including that cases are missing conditionally at random (MAR) and that censoring is noninformative. However, given the similarities between the final analytical sample and the (larger) sample of all cases for which (pre-)baseline variables are observed, we do not believe that a multiple imputation procedure to account for missingness on time-varying variables would result in substantially different findings (Appendix Table A3).Another limitation, or caveat, concerns the interpretation of our results. Like most inference 
methods, the results of the g-formula are driven by observed relationships in the empirical data. For example, we show a significant impact of changes in marriage behaviour on fertility behaviour. However, we do not model a change in the underlying meaning of marriage. Similarly, our post-birth employment scenario does not include the anticipation of full-time employment after birth that would accompany any realworld policy. We note that this limitation is unlikely to be surmounted by an alternative method, but instead requires different data, such as (accurate) data on attitudes and intentions, or data on policies that are implemented in the real world. That said, a more nuanced application of the same method may be achieved by using more fine-grained (e.g. monthly) data, if such data were available, for example to test the specific effects of monthly variation in maternity leave policies.

One benefit of the g-formula is that it allows us to make generalisations at the population level. When the interest is in making statements about the population, as is common for example in sociology and demography, this provides advantages over alternative methods that sacrifice external validity. In addition, our example could be extended fairly easily to model additional (or more nuanced) scenarios, for example the impact of targeted policies, or the combined effect of changes to more than one socioeconomic determinant. As is almost always the case in research on fertility, our analysis focusses on women, but could also be repeated for men, or for specific subgroups. In addition, future research could examine the extent to which the findings shown here can be generalized over time (to other UK birth cohorts) or across space (to other countries).

In settings with larger analytical samples, it may be possible to model the fertility process, and its determinants, with greater complexity. As well as enabling the inclusion of a richer set of covariates, this could enable the links between fertility and its determinants to be modelled using lags of more than one year (similar to an autoregressive analysis of time series data: AR2, AR3, etc.). The outcome, births, could 
be modelled with greater nuance, for example by including stillbirths and conceptions not resulting in pregnancy. It would be informative to incorporate the effect of adoptions and child mortality, as well as the proximate determinants of fertility that are not considered here, in particular: contraception, abortion, miscarriages and fecundability. At the moment, all of these factors are absorbed into the time-varying mediating processes, but if a rich enough data source were used they could be investigated in order to gain a deeper understanding of mediation.

To conclude, our study not only shows the many potential benefits of using the g-formula, but also how it can be developed beyond previous applications. Most methods that have been used to study fertility do not enable researchers to estimate the direct and indirect effects of time-varying determinants, or their role as mediating factors. Indeed, we believe that the same can be said for most methods that are used more generally to study life course process. In this paper, we have shown how the gformula can be used to carry out dynamic mediation analysis, as well as demonstrating for the first time how to carry out sensitivity analysis for unobserved confounding when using the g-formula. Our analysis highlights the potential benefits of the method for a range of life course topics. For example, it could be usefully applied to the study of linked couple-level decision-making based on individual-level data. Such analysis is often prevented, or at least made difficult, because of the mediating interrelationships between the life course of both partners. Along similar lines, this approach could be used to study migration, which is a mediating process in the life course of most individuals. Time-varying mediation is methodologically complex, and yet as we have shown, the g-formula provides social scientists with a sophisticated and flexible tool for understanding this complexity, while also providing meaningful results that are generalizable to the population. 


\section{References}

Aassve, A., Burgess, S., Propper, C., \& Dickson, M. (2006). Employment, family union and childbearing decisions in Great Britain. Journal of the Royal Statistical Society: Series A (Statistics in Society), 169(4), 781-804.

Adserà, A., (2005). Vanishing children: From high unemployment to low fertility in developed countries. Am. Econ. Rev. 95, 189-193.

Andersson, G. (2004). Childbearing after Migration: Fertility Patterns of Foreign-born Women in Sweden. International Migration Review, 38(2), 747-774.

Balbo, N., Billari, F. C., \& Mills, M. (2012). Fertility in Advanced Societies: A Review of Research. European Journal of Population/Revue européenne de Démographie, 1-38.

Beaujouan, É., \& Ní Bhrolcháin, M. (2011). Cohabitation and marriage in Britain since the 1970s. Population Trends, 145, 35-59.

Becker, G. S. (1981). A Treatise on the Family. Cambridge: Harvard University Press.

Becker, G. S., Duesenberry, J. S., \& Okun, B. (1960). An economic analysis of fertility. Columbia University Press.

Berrington, A., \& Pattaro, S. (2014). Educational differences in fertility desires, intentions and behaviour: A life course perspective. Advances in Life Course Research, 21, 10-27. doi:10.1016/j.alcr.2013.12.003

Berrington, A., Stone, J., \& Beaujouan, E. (2015). Educational differences in timing and quantum of childbearing in Britain: A study of cohorts born 1940-1969. Demographic Research, 33, 733-764. doi:10.4054/DemRes.2015.33.26

Bijlsma, M. J., Tarkiainen L, Myrskylä M, Martikainen P. (2017). Unemployment and subsequent depression: A mediation analysis using the parametric G-formula. Social Science \& Medicine, 194: 142-150. 
Billari, F. C., \& Kohler, H.-P. (2004). Patterns of low and lowest-low fertility in Europe. Population Studies, 58(2), 161-176.

doi:10.1080/0032472042000213695

Bongaarts, J., (2016). Africa's Unique Fertility Transition. Popul. Dev. Rev. n/a-n/a. https://doi.org/10.1111/j.1728-4457.2016.00164.x

Bongaarts, J., Mensch, B.S., Blanc, A.K., (2017). Trends in the age at reproductive transitions in the developing world: The role of education. Popul. Stud. 71, 139154. https://doi.org/10.1080/00324728.2017.1291986

Brien, M. J., Lillard, L. A., \& Waite, L. J. (1999). Interrelated family-building behaviors: Cohabitation, marriage, and nonmarital conception. Demography, 36(4), 535-551. doi:10.2307/2648089

Buhr, P., \& Huinink, J. (2014). Fertility analysis from a life course perspective. Advances in Life Course Research, 21, 1-9. doi:10.1016/j.alcr.2014.04.001

Carnegie, N. B., Harada, M., \& Hill, J. L. (2016). Assessing Sensitivity to Unmeasured Confounding Using a Simulated Potential Confounder. Journal of Research on Educational Effectiveness, 9(3), 395-420. doi:10.1080/19345747.2015.1078862

Cartwright, N. (2011). Evidence, external validity and explanatory relevance. Oxford University Press.

Chamberlain, J., \& Gill, B. (2005). Fertility and mortality. In Focus on people and migration (pp. 71-89). Springer. http://link.springer.com/chapter/10.1007/9781-349-75096-2_5. Accessed 3 April 2017

Champion, A. G., \& Falkingham, J. (Eds.). (2016). Population change in the United Kingdom. London; New York: Rowman \& Littlefield International. 
Cleland, J., \& Wilson, C. (1987). Demand Theories of the Fertility Transition: An Iconoclastic View. Population Studies, 41(1), 5-30. doi:10.1080/0032472031000142516

Coale, A. J., \& Watkins, S. C. (1986). The Decline of Fertility in Europe: The Revised Proceedings of a Conference on the Princeton European Fertility Project. Princeton University Press.

Cohen, J. E., Kravdal, O., \& Keilman, N. (2011). Childbearing impeded education more than education impeded childbearing among Norwegian women. Proceedings of the National Academy of Sciences, 108(29), 11830-11835. doi:10.1073/pnas.1107993108

Daniel, R. M., Cousens, S. N., De Stavola, B. L., Kenward, M. G., \& Sterne, J. A. C. (2013). Methods for dealing with time-dependent confounding. Statistics in Medicine, 32(9), 1584-1618. doi:10.1002/sim.5686

Davis, K., \& Blake, J. (1956). Social Structure and Fertility: An Analytic Framework. Economic Development and Cultural Change, 4(3), 211-235.

Dribe, M., Oris, M., \& Pozzi, L. (2014). Socioeconomic status and fertility before, during, and after the demographic transition: An introduction. Demographic Research, 31, 161-182. doi:10.4054/DemRes.2014.31.7

Dribe, M., Breschi, M., Gagnon, A., Gauvreau, D., Hanson, H.A., Maloney, T.N., Mazzoni, S., Molitoris, J., Pozzi, L., Smith, K.R., Vézina, H., (2017). Socioeconomic status and fertility decline: Insights from historical transitions in Europe and North America. Popul. Stud. 71, 3-21. https://doi.org/10.1080/00324728.2016.1253857

Engelhardt, H., Kohler, H.-P., \& Prskawetz, A. (2009). Causal analysis in population studies: concepts, methods, applications. Springer. 
Esping-Andersen, G., \& Billari, F. C. (2015). Re-theorizing Family Demographics. Population and Development Review, 41(1), 1-31. doi:10.1111/j.17284457.2015.00024.x

Forste, R., \& Tienda, M. (1996). What's Behind Racial and Ethnic Fertility Differentials? Population and Development Review, 22, 109-133. doi: $10.2307 / 2808008$

Gerster, M., Ejrnæs, M., \& Keiding, N. (2014). The Causal Effect of Educational Attainment on Completed Fertility for a Cohort of Danish Women-Does Feedback Play a Role? Statistics in Biosciences, 6(2), 204-222. doi:10.1007/s12561-013-9102-0

Goisis, A., \& Sigle-Rushton, W. (2014). Childbearing Postponement and Child Wellbeing: A Complex and Varied Relationship? Demography, 51(5), 1821-1841. doi:10.1007/s13524-014-0335-4

Goldscheider, F., Bernhardt, E., \& Lappegård, T. (2015). The Gender Revolution: A Framework for Understanding Changing Family and Demographic Behavior. Population and Development Review, 41(2), 207-239. doi:10.1111/j.17284457.2015.00045.x

Greenland, S., Pearl, J., \& Robins, J. M. (1999). Causal diagrams for epidemiologic research. Epidemiology, 37-48.

Guetto, Raffaele, Ruud Luijkx, and Stefani Scherer. (2015). "Religiosity, Gender Attitudes and Women's Labour Market Participation and Fertility Decisions in Europe.” Acta Sociologica 58 (2): 155-72. https://doi.org/10.1177/0001699315573335. 
Heaton, T.B., Forste, R., Otterstrom, S.M., (2002). Family transitions in Latin America: first intercourse, first union and first birth. Int. J. Popul. Geogr. 8, 1-15. https://doi.org/10.1002/ijpg.234

Hirschman, C. (1994). Why Fertility Changes. Annual Review of Sociology, 20, $203-$ 233.

Hobcraft, J. (1996). Fertility in England and Wales: A Fifty-Year Perspective. Population Studies, 50(3), 485-524. doi:10.1080/0032472031000149586

Hoem, J.M., (2008). Special Collection (Preface): Childbearing Trends and Policies in Europe. Demogr Res. 19, 1-4. https://doi.org/10.4054/DemRes.2008.19.1

Hoem, B., \& Hoem, J. M. (1989). The Impact of Women's Employment on Second and Third Births in Modern Sweden. Population Studies, 43(1), 47-67. doi:10.1080/0032472031000143846

Huinink, J., \& Kohli, M. (2014). A life-course approach to fertility. Demographic Research, 30, 1293-1326. doi:10.4054/DemRes.2014.30.45

Jalovaara, M., Neyer, G., Andersson, G., Dahlberg, J., Dommermuth, L., Fallesen, P., Lappegård, T., (2018). Education, Gender, and Cohort Fertility in the Nordic Countries. Eur. J. Popul. https://doi.org/10.1007/s10680-018-9492-2

Johnson-Hanks, J., Bachrach, C. A., Morgan, S. P., \& Kohler, H.-P. (2011). Understanding family change and variation : toward a theory of conjunctural action. Dordrecht; New York: Springer.

Keil, A. P., Edwards, J. K., Richardson, D. R., Naimi, A. I., \& Cole, S. R. (2014). The parametric G-formula for time-to-event data: towards intuition with a worked example. Epidemiology (Cambridge, Mass.), 25(6), 889-897.

doi:10.1097/EDE.0000000000000160 
Kneale, D., \& Joshi, H. (2008). Postponement and childlessness - Evidence from two British cohorts. Demographic Research, 19, 1935-1968. doi:10.4054/DemRes.2008.19.58

Kravdal, Ø., Rindfuss, R.R., (2008). Changing relationships between education and fertility: A study of women and men born 1940 to 1964. Am. Sociol. Rev. 73, $854-873$.

Kulu, H., \& Steele, F. (2013). Interrelationships Between Childbearing and Housing Transitions in the Family Life Course. Demography, 50(5), 1687-1714. doi:10.1007/s13524-013-0216-2

Kulu, H., \& Washbrook, E. (2014). Residential context, migration and fertility in a modern urban society. Advances in Life Course Research, 21, 168-182. doi:10.1016/j.alcr.2014.01.001

Lee, R., \& Mason, A. (2010). Fertility, Human Capital, and Economic Growth over the Demographic Transition. European Journal of Population / Revue européenne de Démographie, 26(2), 159-182. doi:10.1007/s10680-009-9186-х

Lesthaeghe, R. (1983). A Century of Demographic and Cultural Change in Western Europe: An Exploration of Underlying Dimensions. Population and Development Review, 9(3), 411-435. doi:10.2307/1973316

Lesthaeghe, R. (2010). The unfolding story of the second demographic transition. Population and development review, 36(2), 211-251.

Lillard, L. A., \& Waite, L. J. (1993). A joint model of marital childbearing and marital disruption. Demography, 30(4), 653-681.

Lin, S.-H., Young, J., Logan, R., Tchetgen Tchetgen, E. J., \& VanderWeele, T. J. (2017). Parametric Mediational g-Formula Approach to Mediation Analysis with 
Time-varying Exposures, Mediators, and Confounders: Epidemiology, 28(2), 266-274. doi:10.1097/EDE.0000000000000609

Lorimer, F. (1956). Culture and Human Fertility. Journal of School Health, 26(4), 136136. doi:10.1111/j.1746-1561.1956.tb00823.x

Macura, M., \& Beets, G. (2002). Dynamics of fertility and partnership in Europe: insights and lessons from comparative research Vol. I / ed. by Miroslav Macura and Gijs Beets. Vol. I / ed. by Miroslav Macura and Gijs Beets. New York: United Nations.

Martin, T.C., (1995). Women's Education and Fertility: Results from 26 Demographic and Health Surveys. Stud. Fam. Plann. 26, 187. https://doi.org/10.2307/2137845

Mclanahan, S. (2004). Diverging destinies: How children are faring under the second demographic transition. Demography, 41(4), 607-627. doi:10.1353/dem.2004.0033

Milewski, N. (2010). Fertility of Immigrants: A two-generational approach in Germany. Berlin, Heidelberg: Springer Berlin Heidelberg. http://link.springer.com/10.1007/978-3-642-03705-4. Accessed 19 January 2017

Moffitt, R. (2003). Causal analysis in population research: An economist's perspective. Population and Development Review, 29(3), 448-458.

Moffitt, R. (2005). Remarks on the Analysis of Causal Relationships in Population Research. Demography, 42(1), 91-108.

Neels, K., Murphy, M., Ní Bhrolcháin, M., Beaujouan, É., 2017. Rising Educational Participation and the Trend to Later Childbearing. Popul. Dev. Rev. 43, 667693. https://doi.org/10.1111/padr.12112

Neyer, G., Lappegård, T., \& Vignoli, D. (2013). Gender Equality and Fertility: Which Equality Matters?: Egalité de genre et fécondité : de quelle égalité s'agit-il? 
European Journal of Population / Revue européenne de Démographie, 29(3), 245-272. doi:10.1007/s10680-013-9292-7

Ní Bhrolcháin, M. \& Beaujouan, É., 2012. Fertility postponement is largely due to rising educational enrolment. Popul. Stud. 1-17. https://doi.org/10.1080/00324728.2012.697569

O’Leary, L., Natamba, E., Jefferies, J., \& Wilson, B. (2010). Fertility and partnership status in the last two decades. Population Trends, 140, 5-35.

ONS. (2016). Childbearing for women born in different years, England and Wales: 2015 (published online). Office for National Statistics. https://www.ons.gov.uk/peoplepopulationandcommunity/birthsdeathsandmarria ges/conceptionandfertilityrates/bulletins/childbearingforwomenbornindifferenty earsenglandandwales/2015/pdf. Accessed 3 April 2017

Pearl, J. (2001). Direct and indirect effects. In: Proceedings of the seventeenth conference on uncertainty in artificial intelligence, p. 411-20. http://ftp.cs.ucla.edu/pub/stat_ser/R273-U.pdf

Perelli-Harris, B., Sigle-Rushton, W., Kreyenfeld, M., Lappegård, T., Keizer, R., \& Berghammer, C. (2010). The educational gradient of childbearing within cohabitation in Europe. Population and development review, 36(4), 775-801.

Reher, D., Requena, M., (2015). The mid-twentieth century fertility boom from a global perspective. Hist. Fam. 20, 420-445. https://doi.org/10.1080/1081602X.2014.944553

Rendall, M. S., \& Smallwood, S. (2003). Higher qualifications, first-birth timing and further childbearing in England and Wales. Population Trends, 111, 18-26.

Robins, J. M. (1986). A new approach to causal inference in mortality studies with a sustained exposure period - application to control of the healthy worker survivor 
effect. Mathematical Modelling, 7(9-12), 1393-1512. doi:10.1016/02700255(86)90088-6

Robins, J.M., \& Greenland S. (1992). Identifiability and exchangeability for direct and indirect effects. Epidemiology, 3(2):143-155.

Robins, J. M., \& Hernán, M. A. (2009). Chapter 23: Estimation of the causal effects of time-varying exposures. In Longitudinal data analysis (pp. 553-599). Chapman \& Hall/CRC.

Sigle-Rushton, W. (2008). England and Wales: Stable fertility and pronounced social status differences. Demographic research, 19(15), 455-502.

Steele, F., Joshi, H., Kallis, C., \& Goldstein, H. (2006). Changing compatibility of cohabitation and childbearing between young British women born in 1958 and 1970. Population Studies, 60(2), 137-152. doi:10.1080/00324720600598009

Steele, F., Kallis, C., Goldstein, H., \& Joshi, H. (2005). The relationship between childbearing and transitions from marriage and cohabitation in Britain. Demography, 42(4), 647-673.

UK Data Archive. (2016). 1970 British Cohort Study. University of Essex, Institute for Social and Economic Research.

Upchurch, D. M., Lillard, L. A., \& Panis, C. W. (2002). Nonmarital childbearing: Influences of education, marriage, and fertility. Demography, 39(2), 311-329.

van de Kaa, D. J. (1987). Europe’s Second Demographic Transition. Population Bulletin, 42(1). Accessed 16 August 2014

VanderWeele, T. J. (2014). A unification of mediation and interaction: a 4-way decomposition. Epidemiology, 25(5): 749-61.

VanderWeele, T. J. (2015). Explanation in Causal Inference: Methods for Mediation and Interaction (1st edition.). New York: Oxford University Press. 
Vanderweele, T. J., \& Vansteelandt, S. (2009). Conceptual issues concerning mediation, interventions and composition. Statistics and Its Interface, 2(4), 457-468. doi:10.4310/SII.2009.v2.n4.a7

Wang, A., \& Arah, O. A. (2015). G-computation demonstration in causal mediation analysis. European Journal of Epidemiology, 30(10), 1119-1127. doi:10.1007/s10654-015-0100-z 